\title{
REVIEW
}

\section{Night eating syndrome: implications for severe obesity}

\author{
$\mathrm{J} \mathrm{Cleator}^{1}, \mathrm{~J} \mathrm{Abbott}^{2}, \mathrm{P} \mathrm{Judd}^{3}, \mathrm{C}$ Sutton $^{3}$ and JPH Wilding ${ }^{1}$
}

Night eating syndrome (NES) was first identified in 1955 by Stunkard, a psychiatrist specialising in eating disorders (ED). Over the last 20 years considerable progress has been made in defining NES as a significant clinical entity in its own right and it has now been accepted for inclusion in the fifth edition of the Diagnostic and Statistical Manual of Mental Disorders (DSM-5) due for publication in 2013. NES is considered a dysfunction of circadian rhythm with a disassociation between eating and sleeping. Core criteria include a daily pattern of eating with a significantly increased intake in the evening and/or night time, as manifested by one or both of the following: at least $25 \%$ of food intake is consumed after the evening meal or at least two episodes of nocturnal eating per week. An important recent addition to core criteria includes the presence of significant distress and/or impairment in functioning. Stunkard's team recommend further investigation on the pathogenesis of NES, in particular its relationship with traumatic life events, psychiatric comorbidity, the age of onset of NES and course of NES over time. The relationship between NES and other ED also requires further clarification as night-eaters exhibit some features of other ED; previous guidance to separate NES from other ED may have hindered earlier characterisation of NES. Evidence from European and American studies suggests NES features strongly in populations with severe obesity. The complex interplay between depression, impaired sleep and obesity-related comorbidity in severely obese individuals makes understanding NES in this context even more difficult. This review examines evidence to date on the characterisation of NES and concludes by examining the applicability of current NES criteria to individuals with severe obesity.

Nutrition and Diabetes (2012) 2, e44; doi:10.1038/nutd.2012.16; published online 10 September 2012

Keywords: obesity; night eating; sleep; circadian rhythm

\section{INTRODUCTION}

The obesity epidemic continues to impact heavily on the health economy, and the need for successful and enduring obesity treatments is essential. Recent years have seen sustained attempts to understand the contribution of disordered eating patterns to the development of obesity. Considerable progress has been made in understanding night eating syndrome (NES), a cluster of behaviours first identified in 1955 by Stunkard, ${ }^{1}$ a psychiatrist specialising in eating disorders (ED). This narrative review describes the evolution of NES from initial identification to current conceptualisation. Methods of identification, prevalence in varying populations, behavioural and clinical characteristics, and treatment options are discussed. Evolving evidence of the relationship between NES and other ED, sleep-related ED, sleep, depression and anxiety is also considered. The paper concludes by examining the relationship of NES with obesity and the applicability of current NES criteria to a severely obese population.

\section{METHODS}

The Medline, Scopus, Psychlnfo and CINAHL databases were searched for all studies published between 1955 and January 2012. One-hundred and ninty-one papers were found using the search terms of NES, night-eating (NE), late night eating, NE behaviour and nocturnal eating. Results were filtered to return studies of human subjects published in English. Only original research was considered for inclusion. The conceptualisation of NES is still evolving, thus papers were not excluded on the grounds of sample size as even single case reports may be important indicators of future understanding of NES. Reviews, commentaries, reports from professional and non peer-reviewed publications and case reports of other syndromes where discussion of NE was incidental were excluded, yielding 84 studies for potential inclusion, of which 73 have been included in this review.

\section{EVOLUTION OF DIAGNOSTIC CRITERIA}

NES is now considered a dysfunction of circadian rhythm with a disassociation between eating and sleeping, characterised by a phase onset delay of morning appetite and continuation of evening eating. ${ }^{2,3}$ Current diagnostic criteria proposed by the International NES Working Group in 2008 at the First International Night Eating Symposium are listed in Table 1.4

Developments in the conceptualisation of NES have been hindered over time by the adoption of differing diagnostic criteria by researchers from various disciplines as summarised in Table 2 . Thirty years after the originally proposed criteria of 'morning anorexia', 'hyperphagia until midnight on 50\% of nights' and 'sleep onset insomnia', the emotional component of 'eating with tension' and 'without enjoyment' was added, then removed again when Stunkard revisited the syndrome in 1996. ${ }^{1,5-7}$ Refinements to the original criteria at that time included no appetite for breakfast, $50 \%$ or more of food intake after 1900 hours and trouble getting to sleep and/or staying asleep, as well as nocturnal awakenings to eat. Further refinements in 2003 sought to differentiate NES from other ED, emphasise the nocturnal eating

\footnotetext{
${ }^{1}$ Department of Obesity \& Endocrinology, University of Liverpool, Liverpool, UK; ${ }^{2}$ School of Psychology, University of Central Lancashire, Preston, UK and ${ }^{3}$ School of Health, University of Central Lancashire, Preston, UK. Correspondence: Dr J Cleator, School of Nursing, Midwifery \& Social Work, University of Manchester, Jean McFarlane Building, Oxford Road, Manchester M13 9PL, UK.

E-mail: jacqueline.cleator@manchester.ac.uk

Received 25 July 2012; accepted 25 July 2012
} 
Table 1. 2010 Criteria for NES (all of A-F need to be met)

\begin{tabular}{|c|c|c|}
\hline \multirow[t]{2}{*}{$\bar{A}$} & Core criterion: & \\
\hline & $\begin{array}{l}\text { Daily pattern of eating demonstrates a significantly increased } \\
\text { intake in the evening and/or night time, as manifested by one or } \\
\text { both of the following: }\end{array}$ & $\begin{array}{l}\text { (1) At least } 25 \% \text { of food intake is consumed after the evening } \\
\text { meal. } \\
\text { (2) At least two episodes of nocturnal eating per week. }\end{array}$ \\
\hline B & $\begin{array}{l}\text { Core criterion: } \\
\text { Awareness and recall of evening and nocturnal episodes are } \\
\text { present }\end{array}$ & \\
\hline \multirow[t]{2}{*}{ C } & Core descriptors: & \\
\hline & $\begin{array}{l}\text { The clinical picture is characterised by at least three of the } \\
\text { following features: }\end{array}$ & $\begin{array}{l}\text { (1) Lack of desire to eat in the morning and/or breakfast is } \\
\text { omitted on four or more mornings per week. } \\
\text { (2) Presence of a strong urge to eat between dinner and sleep } \\
\text { onset and/or during the night. } \\
\text { (3) Presence of a belief that one must eat to initiate or return to } \\
\text { sleep. } \\
\text { (4) Sleep onset and or/sleep maintenance insomnia are present } \\
\text { four or more nights per week. } \\
\text { (5) Mood is frequently depressed and/or mood worsens in the } \\
\text { evening. }\end{array}$ \\
\hline D & $\begin{array}{l}\text { Core criterion: } \\
\text { The disorder associated with significant distress and/or } \\
\text { impairment in functioning }\end{array}$ & \\
\hline $\mathrm{E}$ & $\begin{array}{l}\text { Core criterion: } \\
\text { The disordered pattern of eating has been maintained for at least } \\
3 \text { months }\end{array}$ & \\
\hline $\mathrm{F}$ & $\begin{array}{l}\text { Core criterion: } \\
\text { The disorder is not secondary to substance abuse or dependence, } \\
\text { medical disorder, medication or another psychiatric disorder. }\end{array}$ & \\
\hline
\end{tabular}

Table 2. Evolution of diagnostic criteria for NES from 1955-2003

\begin{tabular}{|c|c|c|}
\hline Author & Year & Criteria \\
\hline Stunkard ${ }^{1}$ & 1955 & $\begin{array}{l}\text { Morning anorexia, } \\
\text { nocturnal hyperphagia until midnight on } 50 \% \text { of nights, } \\
\text { sleep onset insomnia }\end{array}$ \\
\hline Kuldau $^{5}$ & 1986 & $\begin{array}{l}\text { Morning anorexia, } \\
\text { eating later in day, } \\
\text { on and off evening eating without enjoyment, } \\
\text { sleep onset insomnia, } \\
\text { evening tension }\end{array}$ \\
\hline Rand $^{6}$ & 1993 & $\begin{array}{l}\text { Morning anorexia, } \\
\text { excessive evening eating, } \\
\text { evening tension and/or feeling upset, } \\
\text { insomnia }\end{array}$ \\
\hline Stunkard $^{7}$ & 1996 & $\begin{array}{l}\text { No appetite for breakfast, } \\
50 \% \text { or more of food intake after } 1900 \text { hours, } \\
\text { trouble getting to sleep and/or staying asleep }\end{array}$ \\
\hline Birketvedt ${ }^{23}$ & 1999 & $\begin{array}{l}\text { Morning anorexia } \\
\text { evening overeating (including at least } 50 \% \text { of food intake after } 1800 \text { hours) } \\
\text { insomnia }\end{array}$ \\
\hline Powers $^{16}$ & 1999 & $\begin{array}{l}\text { More than } 25 \% \text { of total energy intake after evening meal, } \\
\text { trouble sleeping, } \\
\text { appetite in morning }\end{array}$ \\
\hline Ceru-Bjork $^{12}$ & 2001 & $\begin{array}{l}\text { As per Stunkard }{ }^{7} \text { and } \\
\text { waking up at night and getting out of bed to eat and/or after having gone to bed, getting out of bed } \\
\text { to eat or eating in bed }\end{array}$ \\
\hline Napolitano $^{18}$ & 2001 & $\begin{array}{l}\text { Morning anorexia, } \\
\text { evening hyperphagia, } \\
\text { emotional distress, } \\
\text { sleep difficulties }\end{array}$ \\
\hline Adami $^{14}$ & 2002 & $\begin{array}{l}\text { Morning anorexia, } \\
\text { more than } 25 \% \text { of total energy intake after evening meal, } \\
\text { trouble falling and/or staying asleep most nights }\end{array}$ \\
\hline Stunkard $^{8}$ & 2003 & $\begin{array}{l}\text { Morning anorexia, even if subject eats breakfast, } \\
\text { evening hyperphagia. At least } 50 \% \text { of the daily caloric intake is consumed in snacks after the last evening meal, } \\
\text { awakenings at least once a night, at least } 3 \text { nights a week, } \\
\text { aonsumption of high-calorie snacks during the awakenings on frequent occasions, } \\
\text { the pattern occurs for a period of at least } 3 \text { months, } \\
\text { absence of other eating disorders }\end{array}$ \\
\hline
\end{tabular}

and account for cultural differences by removing the 1900 hours time restriction. ${ }^{8}$ By 2008 these criteria were acknowledged as too restrictive and were broadened again to include 'at least $25 \%$ of food intake consumed after the evening meal and/or at least two episodes of nocturnal eating per week'. The emotional component of distress also reappeared as a core criterion. ${ }^{9}$ 


\section{PREVALENCE}

Interpretation of prevalence data is problematic as criteria and methods of identification vary between studies. Viewed as a whole, evidence suggests a general trend for prevalence to be low in general population samples and to increase with the degree of obesity (Table 3). Early studies comparing healthy weight controls and severely obese individuals indicated prevalence ranging between $0.5-1.5 \%$ and $15-25 \%$, respectively. $5,6,10,11$ Later studies in obese populations estimate prevalence between $8.9-14 \%{ }^{7,12,13}$ Prevalence in severe obesity is mixed depending on the criteria adopted. ${ }^{7,14-16}$ Two early studies reported exceptionally high rates of 51 and $43 \% .{ }^{17,18}$ Prevalence in subjects awaiting bariatric surgery based on graded diagnostic criteria was estimated at $1.9 \%$ (strictest criteria) and $8.9 \%$ across all definitions. ${ }^{19}$ Others note similar variability when different criteria are applied to the same sample. $^{20}$ On the basis of 'conservative criteria' $25 \%$ of a psychiatric outpatient population reported NES and were more likely to have a higher body mass index (BMl; mean BMI $33.1 \mathrm{~kg} \mathrm{~m}^{-2}$ vs $27.7 \mathrm{~kg} \mathrm{~m}^{-2}$ ). ${ }^{21}$ A study of self-reported levels of NES in subjects with diabetes based on a single question about eating late at night revealed a prevalence of $9.7 \%{ }^{22}$

\section{BEHAVIOURAL AND CLINICAL CHARACTERISTICS}

A landmark study of NES in American females (mean BMI $28.5 \mathrm{~kg} \mathrm{~m}^{-2}$ ) based on 1996 criteria showed NES and non-NES participants to have similar sleep onset, offset and duration times, but NES individuals woke on an average 3.6 times a night and snacked to return to sleep. ${ }^{23}$ A later American replication study (mean BMI $34.9 \mathrm{~kg} \mathrm{~m}^{-2}$ ), using 2003 criteria, showed similar patterns, with the NES group waking on an average 1.5 times per night and eating during $74 \%$ of the awakenings. ${ }^{24,25}$ Total $24-\mathrm{h}$ energy intake varied only moderately between NES and non-NES individuals in both studies, although NES subjects consumed significantly more of their total energy intake at night as compared with non-NES subjects (56\% vs $15 \%$ and $34.6 \%$ vs $10 \%$, respectively). Psychometric modelling applied retrospectively on the temporal eating, and intake of the study subjects confirmed these differences. ${ }^{26}$

Temporal displacement of other circadian rhythms were noted including phase delays of $1-2.8 \mathrm{~h}$ in two food-regulatory rhythms (leptin and insulin) and in the circadian melatonin rhythm, with a trend for delay in cortisol. Glucose rhythms showed an inverted circadian pattern. Circulating levels of ghrelin, the primary hormone stimulating food intake, were markedly phase advanced by $5.2 \mathrm{~h}$. Reduced amplitudes in the circadian rhythm of food intake, cortisol, ghrelin and insulin, and an increased TSH amplitude were noted. The authors propose that NES may result from disassociations between central (suprachiasmatic nucleus) timing mechanisms and putative oscillators elsewhere in the central nervous system or periphery such as the stomach. Given that altered food intake timings could be causing the hormonal patterns, it is acknowledged that further studies with controlled meal times would be needed to establish cause and effect. ${ }^{2}$

Despite similarities in NES eating behaviour, considerable difference is noted between studies in the average amount consumed by NES individuals after the evening meal. Criteria up to 2003 required an intake of at least $50 \%$, although most researchers considered this unnecessarily restrictive and relaxed this requirement downwards when recruiting for studies. ${ }^{22,27,28}$ Accurate estimation of daily dietary intake during verbal recall is difficult with some studies reporting a tendency for overestimation in NES participants. ${ }^{27,29}$ Individuals in one study verbally reported eating $51 \%$ of their daily energy intake after the evening meal but only recorded $34.9 \%$ in food diaries. ${ }^{29}$ Conversely under-reporting, particularly in overweight and obese individuals, is a common phenomenon with evidence of the degree of under-reporting in epidemiological studies ranging from 10 to $47 \% .^{30}$ Current NES guidelines suggest at least $25 \%$ of

Table 3. Prevalence of night eating symptoms in adults (unless otherwise stated)

\begin{tabular}{|c|c|c|c|c|c|}
\hline Author & Year & Population & $\begin{array}{c}\text { Degree of overweight } \\
\text { Mean BMI }\left(\mathrm{kg} \mathrm{m}^{-2}\right) \\
\% \text { BMI }>30\end{array}$ & $\mathrm{~N}$ & Prevalence (\%) \\
\hline Stunkard ${ }^{1}$ & 1955 & Obesity OPD & $68 \%$ Overweight & 25 & 80 \\
\hline \multirow{2}{*}{ Kuldau $^{5}$} & 1986 & General population & $\begin{array}{l}\text { Normal weight } \\
\text { Normal weight }\end{array}$ & $\begin{array}{c}38 \\
232\end{array}$ & $\begin{array}{c}0 \\
0.5\end{array}$ \\
\hline & & Pre obesity surgery & Morbidly obese & 100 & 15 \\
\hline \multirow[t]{2}{*}{ Rand $^{6}$} & 1993 & General population & 24.9 & 2097 & 1.5 \\
\hline & & Pre obesity surgery & 52 & 255 & 25 \\
\hline \multirow[t]{3}{*}{ Stunkard ${ }^{7}$} & 1996 & Self report BED & 37.8 & 102 & 13.7 \\
\hline & & Weight loss study & 35.3 & 79 & 8.9 \\
\hline & & BED subjects & 35.5 & 40 & 15 \\
\hline Powers ${ }^{16}$ & 1999 & Obesity surgery & 53.4 & 116 & 10 \\
\hline Aronoff ${ }^{17}$ & 2001 & Obesity OPD & 55 & 110 & 51 \\
\hline Ceru-Bjork $^{12}$ & 2001 & Obesity OPD & 40 & 194 & 14 \\
\hline Gluck $^{13}$ & 2001 & Obesity OPD & 36.5 & 76 & 14 \\
\hline Napolitano ${ }^{18}$ & 2001 & $\begin{array}{l}\text { Obesity OPD } \\
\text { Some BED subjects }\end{array}$ & 41.1 & 83 & 43 \\
\hline Adami $^{14}$ & 2002 & Obesity OPD & 43.5 & 166 & 7.8 \\
\hline Anderson $^{68}$ & 2004 & General population (MONICA project) & $10 \%$ & 2111 & 8 \\
\hline Lamerz $^{40}$ & 2005 & $\begin{array}{l}\text { School children } \\
\text { (range } 5-7 \text { years) }\end{array}$ & 15.8 (Mean 51st percentile ${ }^{a}$ ) & 1979 & 1.1 \\
\hline Allison $^{19}$ & 2006 & Pre obesity surgery & 50.4 & 215 & $8.9 / 1.9$ \\
\hline Morse $^{22}$ & 2006 & Diabetes 1 and 2 OPD & $32 \%$ & 714 & 9.7 \\
\hline Colles $^{15}$ & 2008 & Obesity OPD & 44.3 & 129 & 17.1 \\
\hline Lundgren $^{21}$ & 2010 & Psychiatric OPD & 37.2 & 68 & 25 \\
\hline $\operatorname{Root}^{43}$ & 2010 & General population (STAGE project) & $26.6^{\mathrm{b}}$ & 5441 & 7.7 \\
\hline
\end{tabular}

Abbreviations: BED, binge eating disorder; BMI, body mass index; OPD, outpatient department. ${ }^{\mathrm{a}}$ On the basis of the german reference population. ${ }^{\mathrm{b}}$ Highest lifetime BMI. 
food intake is consumed after the evening meal, although the definition of 'evening meal' continues to lack clarity, especially given cultural differences. Lundgren et al. propose 'evening meal' should be classed as the first food eaten after 1700 hours, which could be a 'main meal' or 'snack' if no main meal is eaten. If no food is eaten by 2000 hours, then any food after 2000 hours is classed as 'after the evening meal'. ${ }^{31}$ Future understanding of NES will benefit from consistent methodology for identifying energy intake across studies and explicit definition of the 'evening meal'.

The extent to which individuals with evening hyperphagia, but undisturbed sleep, could be classed as NES was ambiguous based on early criteria. Current criteria now make this explicit, suggesting both evening hyperphagia and/or at least two episodes of nocturnal eating per week' are classed as NES. The predominance of one construct over another continues to be debated. Item response theory analysis of responses from NE questionnaires completed by 1481 individuals suggests key features to be nocturnal eating and/or evening hyperphagia, initial insomnia and night awakening, with morning anorexia and delayed morning meal less important. ${ }^{9}$ Others conclude that evening hyperphagia and nocturnal eating are the same construct and propose a continuum of severity, identifying individuals without nocturnal snacking as 'NES' and nocturnal snackers as 'NES plus nocturnal snacking'. ${ }^{32,33}$ Striegel-Moore et al. $^{34}$ also distinguish between evening-eaters and night-eaters, suggesting NES should be based on eating very late at night.

\section{IDENTIFICATION}

The absence of a consistent method for identifying NES encouraged early researchers to use various methods to establish diagnosis, including interviews, questionnaires based solely on Stunkard's criteria and questionnaires combining other syndromes. ${ }^{12-14}$ An interview conducted by an ED specialist is now considered the gold standard diagnostic tool for NES. Symptom severity is measured with the NE questionnaire (NEQ) ${ }^{35}$ and findings supplemented using the Night Eating Symptom and History Inventory (NESHI), a 17-item interview schedule. ${ }^{29}$

The NEQ underwent several revisions and now contains 14 items and a five-point Likert scale. Validation studies on the current version were published in 2008 combining evidence from three separate NES studies. ${ }^{35}$ Study 1 examined factor structure and internal consistency, and included 1980 persons with selfdiagnosed NES who completed the NEQ on the Internet. The mean score was 33.1 (7.5). Principal components analysis was used to generate four factors (nocturnal ingestions, evening hyperphagia, morning anorexia and low mood/disturbed sleep) with a Cronbach's alpha of 0.70 .

The second study in 81 outpatients diagnosed with NES found acceptable convergent validity of the NEQ with additional measures of $\mathrm{NE}$, disordered eating, sleep, mood and stress. The third study compared scores from obese bariatric surgery candidates with and without NES, and found appropriate discriminant validity of the NEQ. Of 184 individuals, $19(10.3 \%)$ were identified with NES. Mean scores were NES 26.2 (8.1) vs nonNES 16.0 (6.3). The positive predictive value of the NEQ at a score of 25 or higher was low (40.7\%), increasing to $72.7 \%$ at a score of 30 or greater. The negative predictive value was high for cut scores of both 25 and 30 (95.2\% and 94.0\%, respectively). Other researchers have found similar cut points useful, although it is recommended that item 13 which explores awareness during NE be excluded from scoring as this is a diagnostic item distinguishing NES from sleep disorders. When item 13 was excluded from the scores of 399 psychiatric patients the positive predictive value was $62 \%$ using a cut point of 25 and $77 \%$ with a cut point of $30 .{ }^{36}$ Its use is widespread, although the authors advise caution in using it as either a screening or diagnostic tool, suggesting its best use is as a measure of NES symptom severity. ${ }^{35}$

\section{RELATIONSHIP OF NES TO OTHER EDS}

NES is currently classed as an Eating Disorder Not Otherwise Specified (EDNOS) in the Diagnostic \& Statistical Manual of Mental Disorders 4th edition ( DSM-IV) scheme and will be included in the new DSM-5 scheme due for publication in 2013 as a 'Feeding and Eating Condition Not Elsewhere Classified'. Although its classification as an ED seems accepted, its relationship with other EDs remains unclear. Early studies considered NES to be a similar construct to binge ED (BED). 7,18,37,38 Later evidence available at the time NES criteria were updated in 2003 highlighted clear differences between the constructs, thus the absence of other ED was considered necessary for a diagnosis of NES. ${ }^{8,39}$ NES appeared to have a stronger family link and to be more resistant than BED to bariatric surgical intervention. ${ }^{28,40,41}$ NES individuals ate fewer meals in the day and more in the night (1300 calories are consumed during an average binge as opposed to 271 per average night-time snack) than BED and control participants. BED subjects reported less sleep disturbance and morning anorexia and more objective bulimic and overeating episodes, shape and weight concerns, disinhibition and hunger. ${ }^{14,27}$

More recent studies highlight similarities rather than differences and suggest varying degrees of overlap between other ED and NES. $^{32,33}$ In 68 individuals with ED (anorexia nervosa $(n=32)$, bulimia nervosa (BN) $(n=32)$, EDNOS $(n=4)$, mean (SD) BMI $\mathrm{kg} \mathrm{m}^{-2} 21.4(8.5)$ ), $25 \%$ met all current NES criteria. Forty two per cent reported evening hyperphagia and $23 \%$ reported eating at night two or more times per week. ${ }^{31}$ The Swedish Twin Study of Adults identified a genetic correlation of 0.66 between NE and binge eating (BE) in females, indicating a substantial, but not complete, overlap in genetic factors. Males were more likely to report NE behaviours, and moderate heritability for NE was found in both males and females. ${ }^{42,43}$

In acknowledgement of this unclear relationship with other ED, a major shift in emphasis is now proposed. Current criteria state that NES 'should not be secondary to substance abuse or dependence, a medical disorder, medication or another psychiatric disorder'. It is recommended that individuals with NES and sub-threshold symptoms of other ED be classed as NES, but individuals with other ED and some sub-threshold symptoms of NES be classed as non-NES. If both concur, NES should 'defer' to the other ED and the NE aspects be considered symptom dimensions. Future work is required to characterise these relationships better. It may be more beneficial to concentrate less on differences and categorisation and more on common behaviours and cognitions.

Perceived loss of control over aspects of daily living and a tendency to attribute the cause of 'bad' life events to aspects of themselves is a common feature of many individuals with ED. ${ }^{44}$ In $\mathrm{BED}$ and $\mathrm{BN}$, sufferers themselves associate binging with restraint and subsequent loss of control, whether the amount overeaten is objectively large or small, even though the volume of food consumed in the overeating episode is traditionally considered crucial to the definition of a 'binge'. ${ }^{33,45,46}$ Experiencing this blurring between the intensity of the experience and the actual volume eaten (described as 'binge drift') may be a more important predictor of eating-related distress than the amount eaten during the overeating episode itself. ${ }^{47,48}$ It is possible that night-eaters have similar cognitions influencing the strong urge to eat between dinner and sleep onset and/or during the night. Studies in bariatric surgery subjects have put less emphasis on ED diagnosis and more on the influence of perceived loss of control as a predictor of outcome. Bariatric surgery candidates reporting severe emotional disturbance due to loss of control, regardless of BED or NES diagnosis, report increased symptoms of depression $(P<0.001)$, appearance dissatisfaction $(P=0.009)$ and poorer mental health-related quality of life $(P=0.027) .{ }^{15}$ Postoperative follow-up showed uncontrolled eating and grazing to be associated with poor postoperative weight loss and elevated 
psychological distress $\left(P=0.008\right.$ and $P<0.001$, respectively) ${ }^{49}$ Similarly, Goldschmidt et al. ${ }^{50}$ compared the weight, shape concerns and depressive symptoms of 96 adolescents with either $\mathrm{BE}$, overeating with loss of control, overeating without loss of control and a control group with normal eating, and found no distinction between the BE and overeating groups reporting loss of control, with both having significantly higher scores than the control groups. Future NES studies are required to identify whether night-eaters are different from individuals with other ED in how they perceive their control overeating and whether this differs between the day and night.

\section{NES AND SLEEP}

Sleep disturbance is obviously present in NES and the revised criterion requiring sleep disturbance to be present on 4 or more nights a week suggests an attempt to rectify the apparent lack of focus on sleep in earlier criteria. ${ }^{3}$ Laboratory studies have suggested that sleep and wake times are not disturbed and that sleep maintenance insomnia and sleep duration are the main problems. ${ }^{23,25,51}$ During sleep studies, American NES individuals ( mean BMI $36 \mathrm{~kg} \mathrm{~m}^{-2}$ ) showed normal sleep-wake behaviour, but experienced less phase 2 and phase 3 sleep than non-NES controls, resulting in a lower total sleep time and reduced sleep efficiency. ${ }^{3}$

\section{NES AND SLEEP-RELATED EATING DISORDER}

Awareness and recall of nocturnal eating episodes is a requirement of NES and is now included as a core criterion. This is primarily to distinguish NES from the much rarer condition of sleep-related eating disorder (SRED) (formerly NSRED). SRED is classed as a parasomnia, is often accompanied by sleep walking and restless leg syndrome, and may be brought on by sedative hypnotics. It is characterised by bizarre food choices and a compulsion to eat before returning to sleep. Traditionally, it featured 'a half asleep/half awake' state and impaired consciousness while eating at night, although criteria updated in 2005 no longer specify a level of consciousness, exacerbating confusion between the two conditions. ${ }^{52}$ Awareness in NES is assumed to be complete, suggesting a dichotomous classification where awareness is completely present or absent. In practice, studies often fail to report levels of awareness or report varying degrees of awareness. ${ }^{53}$ One video-polysomnographic study showed all NES subjects to be fully aware. ${ }^{54}$ de Zwaan et al. ${ }^{32}$ reported $17 \%$ of 'night-eaters' to have low awareness while $\mathrm{NE}$, together with frequent parasomnias, such as nightmares and somnambulism, and questioned whether NES and SRED are different constructs. It is possible that individuals with NES may initially be reluctant to admit to an apparently shameful and secretive behaviour, but can recall events with further probing. ${ }^{4}$ Including items in the NESHI for defining and reporting awareness more robustly may help future researchers distinguish NES from other sleep disorders.

\section{NES AND DEPRESSION}

Depressed mood features in the 2010 criteria as a key descriptor, as an association between depressive symptoms and NES has been a consistent finding of NES studies. ${ }^{1,22-25,27,38,55}$ In one study as many as $70 \%$ of NES subjects reporting a depressed mood. ${ }^{24}$ NES appears common in individuals with mental illness. Prevalence levels of NES in American outpatient psychiatric populations range from 12.3 to $25 \%$ and some evidence suggests that anti-psychotic medication may exacerbate the symptoms. ${ }^{21,36}$ Higher self-reported rates of neglect and emotional abuse, correlating with elevated depression levels were reported in both BED and NES subjects, in comparison with matched obese controls. ${ }^{56}$ When the Beck Depression Inventory
(BDI) scores of 285 females with BED were compared, at least one nocturnal eating episode in the past 28 days was reported by $14.4 \%$ who were classed as night-eaters. A significant difference was noted in mean BDI scores between the night-eaters and nonnight-eaters (20.9 (s.d. 12.1) vs 14.0 (s.d. 10.1), $P<0.001$ ) even after adjusting for the effects of BE. ${ }^{57}$ Depression in NES follows an atypical pattern with distinctive circadian features. Mood is usually better in the morning and worse during the evening and night, unlike depression which is worse in the morning and improves throughout the day. ${ }^{13,23,51,58}$

\section{NES AND ANXIETY}

Biochemical findings of increased circadian secretion of cortisol in early studies, supported the theory that NES subjects have an overexpressed hypothalamic pituitary adrenal axis with an attenuated response to stress. ${ }^{51,59}$ Night anxiety appears more prevalent in adults with NES than adults with $\mathrm{BED}_{1}^{60}$ and similar elevated levels of psychological stress and depression were found in morbidly obese nocturnal snackers. ${ }^{33}$ An individual's perception of control over a stressful situation may determine emotional response and predict the most likely coping strategies that will be adopted. ${ }^{61}$ Non-obese NES individuals have been shown to have greater levels of stress and anxiety than individuals without NES and to be significantly more likely to develop other coping mechanisms such as substance abuse $(30.6 \%$ vs $8.3 \%) .{ }^{58}$ Disturbed sleep is also a common maladaptive response with individuals predisposed to vulnerability to stress often reacting to stressful events by internalising their reaction, which in turn leads to emotional arousal and physical activation during sleep. ${ }^{62}$ In one study poor sleepers viewed themselves less favourably than good sleepers describing themselves as 'bad' and 'weak' and less frequently having a good time with their family as a child, feeling good as a child and with more childhood eating problems. This internalising pattern of somatisation focused on eating and sleeping supports the proposed psychological profile of nighteaters as anxiety-prone personalities.

It is this association with stress and anxiety that makes NES more than a cluster of loosely collected behaviours but a distinct entity in its own right requiring therapeutic intervention and suitable for inclusion in DSM-5. ${ }^{63}$ Significant distress and/or impairment in functioning is now included as a core criterion along with the requirement that symptoms be maintained for a minimum of 3 months. Excluding acute events temporarily disrupting behaviour aligns NES with criteria for other ED, although evidence suggests NES is a chronic condition with the mean duration of NE ranging from 5 to 17.4 years across studies. ${ }^{32}$ It is possible that NES starts out as a coping response to a particular stressor that turns into a habit. ${ }^{1}$ Evidence as to the nature of individual stressors on the development of NES is in its infancy. The timing of sexual abuse has been shown to coincide with the onset of NE in BN and BED adolescents. ${ }^{64}$ The most frequently reported cause of sleeping difficulties due to increased arousal is work-related stress. ${ }^{65}$ Its role in the pathogenesis of NES is unclear as work status is generally not reported in NES studies. Work may also have a positive stabilising function by regulating social rhythms and anchoring bed and rising time. ${ }^{66}$ Future studies need to account for work status, both as an objective measure of functioning and as an influencing factor on the development of NES.

\section{NES AND OBESITY}

The relationship between obesity and NES seems particularly complex. One behavioural study found no difference in total daily energy intake between night-eaters and control subjects. ${ }^{23}$ Similar results were found initially in a second study, but re-analysis using additional participants found the intake of night-eaters to be 
greater than that of non-night-eaters. ${ }^{25,26}$ The NHANES III health and nutrition survey also found the intake of night-eaters to be increased. ${ }^{34}$ It is possible that obesity may be either the cause or the effect of NES depending on the initial trigger for NE behaviour and the age at which it first developed. Evidence is limited mainly to cross-sectional studies, with self-reports of weight change, diagnosis and varying diagnostic criteria, making interpretation of causality more difficult. The questionnaire findings of 21 obese outpatients (mean BMI $37.3 \mathrm{~kg} \mathrm{~m}^{-2}$ ), 40 normal weight individuals (mean BMI $22.5 \mathrm{~kg} \mathrm{~m}^{-2}$ ) and 40 obese individuals (mean BMI $37.9 \mathrm{~kg} \mathrm{~m}^{-2}$ ) were compared. Subjects either self-reported NES or had been previously diagnosed. NES was sometimes present in lean individuals, but was more common in the obese. Although the study was cross-sectional in design, $52 \%$ of obese NES sufferers reported normal weight before the onset of NES. Normal weight night-eaters were significantly younger than obese NES subjects ( 33.1 vs 43.1 years $P<0.01$ ), suggesting NES may be a risk factor for obesity. ${ }^{67}$

Conversely, $60 \%$ of a general population sample responding to a newspaper advert about NE reported being overweight before $\mathrm{NE}$ with no significant difference in the age of onset of NE between normal and overweight participants noted. ${ }^{32}$ In a prospective general population study, with a longitudinal design and a 5- and 10-year follow-up, $9 \%$ of women and $7 \%$ of men responded 'yes' to the question, 'do you get up at night to eat?' at baseline. Obese females responding 'yes' experienced an average 6-year weight gain of $5.2 \mathrm{~kg}(P=0.004)$ compared with $0.9 \mathrm{~kg}$ in obese females who responded 'no'. NE and weight change were not associated among men. ${ }^{68} \mathrm{~A}$ cross-sectional survey in young adults with NES used latent class analysis (LCA) to identify four subtypes of NE symptomatology (depressed and non-depressed late and night-eaters). Obesity was not associated with any of the four classes, or NE in general, with the mean (s.d.) BMI of nighteaters being slightly lower than non-night-eaters (24.8 (5.9) vs 25.4 (6.0)). ${ }^{34}$ No difference in BMI, BMI at age 20 , or maximum BMI was seen between NES and non-NES subjects with class II-III obesity participating in an inpatient weight loss programme. ${ }^{69}$

\section{NES AND CHILDHOOD OBESITY}

Childhood obesity is a known risk factor for adult obesity and is associated with childhood depression and low self-esteem. ${ }^{70}$ It would seem reasonable to assume that a relationship might exist between childhood obesity and NES, although survey data do not support this. In all, $1.1 \%$ of German children aged 5-7 years were identified by their parents as getting up at night to eat. ${ }^{40}$ Similar results were identified in a longitudinal study of children, with $1.5 \%$ reporting eating more than $25 \%$ of total $\mathrm{kCal}$ intake between 2300 and 0500 hours at the age of 11 years. By the age of 19, this had increased to $3.5 \%$, with larger numbers reporting positive on the more relaxed criteria of eating $>25 \%$ of total calorie intake after the last evening meal. Further follow-up of at the age of 21 showed a NES prevalence of $1.6 \%$, in keeping with general adult population levels. ${ }^{71}$ No association with obesity was found in any of these studies, although obese children who may have developed NE as a response to strict parental control over daytime eating may be reluctant to report this.

\section{NES TREATMENTS}

The most successful pharmacological treatment option for NES reported to date is with sertraline, a selective serotonin reuptake inhibitor (SSRI) anti-depressant, which is also known to improve anxiety. A placebo-controlled trial of 8 weeks duration in 34 American subjects with a mean BMI of $32.6 \mathrm{~kg} \mathrm{~m}^{-2}$ confirmed the findings of an earlier small-scale open label study that responders to sertraline experience weight loss, reductions in nocturnal ingestions and in calorie intake after the evening meal. ${ }^{29}$ Given the success of sertraline as a treatment, Stunkard supports the view that the drug may effect a more normal circadian rhythm of food intake through the suprachiasmic nucleus through the restoration of inadequate serotonin levels. ${ }^{72,73} \mathrm{~A}$ pilot SPECT (single photon emission computed tomography) study comparing the serotonin transport uptake ratios of night-eaters with healthy controls has supported the likely involvement of the serotonin system as opposed to other neuroendocrine systems in the pathophysiology of NES. ${ }^{74}$

A pilot study of a 10-session cognitive behavioural therapy (CBT) programme on 25 NES participants (mean BMI $29.5 \mathrm{~kg} \mathrm{~m}^{-2}$ ) has shown promising results and supports earlier reports of behavioural change strategies recommended in a self-help manual. $^{75,76}$ Significant reductions in weight, number of nocturnal ingestions and per cent of daily calorie intake after dinner (all $P<0.0001$ ) were noted, although larger controlled treatment trials on varied populations including those with severe obesity are required to assess fully the efficacy of the programme. ${ }^{76}$ Other small-scale and case report studies describe the use of other anti-depressants, ${ }^{77,78}$ non-pharmacological antidepressant treatments such as Gotu Kola, ${ }^{79}$ Abbreviated Progressive Muscle Relaxation Technique (APMRT) ${ }^{55}$ light therapy ${ }^{80,81}$ and topiramate ${ }^{82}$ as possible treatments for NES. Unfortunately small participant numbers in these studies make interpretation of results difficult.

Interpreting the effect of restrictive weight loss surgical procedures on NES is problematic as the identification and management of ED presurgery varies widely. ${ }^{83}$ Busetto et al. ${ }^{84}$ found no difference in the per cent excess weight loss (\% EWL) in the first 5 years after laparoscopic gastric banding by patients with and without disordered eating. Similar results were seen after gastric bypass, although greater weight loss was related to a reduction in NE episodes. ${ }^{85}$ Others report individuals with NES to have less success postoperatively than those with BED. ${ }^{15}$

\section{APPLICABILITY OF NES CRITERIA TO SEVERE OBESITY}

Obesity and perceived loss of control

Evening hyperphagia is common in severe obesity, NES and BED. An assessment of the energy content of food eaten is required to determine both evening hyperphagia and BED, and may be very high in those with severe obesity. In clinical practice, individuals with severe obesity frequently underreport energy intake, especially if they are also depressed, confounding interpretation further. ${ }^{86}$ Hence, it may be necessary to place more emphasis on determining other behaviours and cognitions such as the timing of eating (EH) or presence of perceived loss of control (BED), to distinguish between these conditions. 'Presence of a belief that one must eat to initiate or return to sleep' is often described as a feature of NES. Yet physical impairment due to obesity and obesity-related comorbidity results in disturbed sleep in many severely obese individuals, only some will get up to eat once awake and others will return to sleep. A greater understanding of the cognitions influencing the urge to eat in some individuals and not others may help to answer why NES individuals find restraint at these high-risk times particularly difficult.

\section{Obesity and distress}

Although NES is characterised by significant distress, interpreting this relationship in the context of severe obesity is problematic. Published evidence of the links between trauma and the onset of obesity is limited. Distress related to NE has been described as 'distress about weight gain, shame of eating and inability to stay within a prescribed calorie deficit'. ${ }^{4}$ However, these are all common features of severe obesity. Future studies examining the origin and nature of distress in obese NES populations may help to clarify this relationship. 
Obesity and morning anorexia

Striegel-Moore's ${ }^{34}$ typology study noted a strong relationship between NE and morning anorexia and the presence of morning anorexia has been a consistent feature of all versions of NES criteria despite difficulties in defining 'morning anorexia' objectively. As a similar relationship also exists between morning anorexia and chronic obesity, its relevance as a distinguishing feature of NES in a severely obese population remains unclear. ${ }^{87}$

\section{The obesity, sleep and depression axis}

The complex interplay between obesity, depression and impaired sleep makes understanding NES behaviour in this context even more difficult. The deleterious effects on health of impaired sleep have been well documented in recent years with long $(\geqslant 9 h)$ and short sleep $\left(\leqslant 6 \mathrm{~h}\right.$ ) duration both linked to increased mortality. ${ }^{88,89}$ A link between sleep duration and obesity has been demonstrated with several large population studies reporting a dose-response relationship between short sleep duration and excess body weight in infants, adolescents and adults of varying ethnicities. ${ }^{90}$ Other studies have shown a link between obesity, short sleep duration and poor sleep quality with improvements in sleep quality noted in obese individuals after a $5 \%$ weight loss. ${ }^{91-93}$ The relationship between rising $\mathrm{BMI}$ and the risk of developing obesity-related comorbidity such as Obstructive Sleep Apnoea (OSA), type 2 diabetes and the metabolic syndrome is also known. ${ }^{94}$ These conditions are also associated with poor sleep quality and excessive day-time sleepiness. ${ }^{95,96}$ Short and long sleep durations increase the risk of developing type 2 diabetes independent of known confounding factors and poor sleep quality is associated with worsening glycaemic control in diabetes. ${ }^{97}$ Increasing BMI is also associated with the debilitating effects of chronic pain, which is in turn associated with depression and anxiety. ${ }^{98}$

Several studies have also demonstrated a link between poor subjective sleep quality and depression. ${ }^{99}$ The neurobiology of disturbed sleep in depression includes disturbances in the electrophysiological architecture and functional deviations in different brain regions, resulting in a decrease in slow wave sleep and increased awakenings. ${ }^{100}$ Various hypothesis also suggest a relationship between obesity and depression. Rosmond considers both to be manifestations of the brain serotonin deficiency and obesity to be the clinical manifestation of a subtype of depression similar to that of atypical depression. ${ }^{101}$ However, the majority of evidence suggests they are separate constructs, having an influencing effect on each other. Obesity can develop subsequent to depression as a result of reduced activity and comfort eating, or obesity-related impairments, such as fatigue and weight-related stigma may result in depression. ${ }^{102,103}$ Improvements in depressed mood are noted after weight loss due to changes in physical appearance and improvements in eating patterns. $^{104}$

\section{Implications for NES}

Short sleep duration is associated with lower leptin and higher ghrelin levels in fasting morning blood, hormone changes which are typically associated with increased appetite and also seen in NES individuals. ${ }^{105,106}$ It is possible that sleep duration may have a part in the pathogenesis of NES, through its association with obesity, ${ }^{105,107}$ although current evidence linking NES and short sleep duration is mixed. O'Reardon et al. ${ }^{24}$ found no difference in sleep duration between NES and non-NES individuals (mean BMI $34.9 \mathrm{~kg} \mathrm{~m}^{-2}$ and $36.7 \mathrm{~kg} \mathrm{~m}^{-2}$, respectively), yet Rogers et al. ${ }^{3}$ noted significantly shorter sleep duration in NES females with similar BMI levels. The relationship between sleep duration and severe obesity is not known. Serotonin promotes satiety and is replaced during sleep. Disturbed sleep may reduce natural levels and increase the need for exogenous sources such as carbohydrates, resulting in obesity. Night snacks consumed in NES are typically carbohydrate rich (73\%), with a high carbohydrate to protein ratio $(7: 1) .^{23}$ Individuals with NES report more difficulty in getting to sleep, but whether this is due to a psychological factor or the physical effect of comorbidity is unclear as sleep patterns are currently not reported consistently in NES studies or measured routinely in obese populations.

NES is common in individuals with schizophrenia and bipolar disorder who are also obese. ${ }^{21,108}$ Higher BDI scores are consistently found in NES subjects in comparison with control groups, with some evidence that degree of obesity may impact on the score. ${ }^{25,56,104}$ Many obese individuals describe overeating in the evening as a result of low mood as a main contributor to their obesity. It is possible that other factors related to obesity such as low self-esteem and shame are contributing to the degree of depression and influencing NE behaviour. Assessing the effect of obesity-related comorbidity on NES is difficult as evidence of the level and impact of OSA and type 2 diabetes in obese NES groups is limited. ${ }^{17,22,33}$ Although Olbrich ${ }^{109}$ suggests the construct of OSA is not closely related to NES, more evidence is required to support this as obesity-related comorbidity is often excluded from NES studies, not reported or assessment is based on incomplete NES criteria. ${ }^{9,22}$

\section{Future directions}

Despite progress being made in the characterisation of NES, unanswered questions remain. It is viewed as both a circadian rhythm and ED. It is either relatively common or rare, depending on which criteria are adopted. Evidence from European and American studies suggests that it may feature strongly in some high-risk groups, such as obese and psychiatric populations. Whether this affects treatment outcomes is unclear with evidence from one weight loss programme suggesting NES participants fared no worse than others without NES. ${ }^{110}$ Further investigation is recommended on its relationship with traumatic life events, psychiatric comorbidity, the age of onset, course over time and effect on circadian rhythm. Bright light therapy is also proposed as a possible treatment. ${ }^{2}$ Recent interest in the clock gene as a potential influence on obesity suggests that future studies examining circadian and endocrine desynchronicity should control for obesity. ${ }^{111}$

Current tools for investigating NES may be inadequate in severe obesity. Despite widespread use, the current NESHI lacks validation and no longer reflects updated criteria. A revised version is due for publication in the near future. Items are required to measure distress and impairment in functioning objectively and items relating to the characterisation of poor sleep and key diagnostic areas such as defining 'supper' and 'degree of awareness' need greater precision. More precise methods to identify calorie intake are also required, although in obese populations it may be less important to estimate exact volumes of food eaten and more important to identify abnormal cognitions and behaviour. Night-eaters exhibit too many features of other ED for this relationship to be ignored and previous guidance to separate NES from other ED was probably counter-productive and a hindrance to its characterisation. Given that all factors identified through principal components analysis in the NEQ are also common in obesity, tools based on other characteristics may help discriminate NES further in obese populations. ${ }^{35}$ It is possible that different tools are required for an underweight teenager and a morbidly obese adult.

\section{Conclusion}

Understanding the significance of factors such as sleep duration, sleep quality, depression and other comorbidity in the development and existence of NES in obese populations is in its infancy. 
Current NES criteria propose that a diagnosis of NES is not appropriate if it is secondary to other medical conditions and yet defining the primary relationship in a severely obese population may not be clear cut. The extent to which each factor is responsible for the causation and maintenance of each other is complex and may differ between individuals. Qualitative NES research is currently limited to reports of patient satisfaction with medical treatment of NES. ${ }^{112}$ Further qualitative studies investigating subjective experiences of individuals with NES and severe obesity may help to identify individual NES-obesity causal pathways and individualise treatment.

\section{CONFLICT OF INTEREST}

Professor Wilding received an educational grant from Roche Products Limited to support the study fees of Jacqueline Cleator while she conducted research into NES at the University of Liverpool, UK. Professors Abbott and Judd and Dr Sutton have no relevant conflict of interest to declare.

\section{REFERENCES}

1 Stunkard A, Grace WJ, Wolff HG. The night-eating syndrome; a pattern of food intake among certain obese patients. Am J Med 1955; 19: 78-86.

2 Goel N, Stunkard AJ, Rogers NL, Van Dongen HP, Allison KC, O'Reardon JP et al. Circadian rhythm profiles in women with night eating syndrome. J Biol Rhythms 2009; 24: 85-94.

3 Rogers NL, Dinges DF, Allison KC, Maislin G, Martino N, O'Reardon JP et al. Assessment of sleep in women with night eating syndrome. Sleep 2006; 29 814-819.

4 Allison KC, Lundgren JD, O'Reardon JP, Geliebter A, Gluck ME, Vinai P et al. Proposed diagnostic criteria for night eating syndrome. Int J Eat Disord 2010; 43: 241-247.

5 Kuldau J, Rand C. The night eating syndrome in the morbidly obese. Int J Eat Disord 1986; 5: 143-148.

6 Rand C, Kuldau J. Morbid obesity: a comparison between a general population and among postoperative obesity surgery patients. Int J Eat Disord 1993; 17: 657-661.

7 Stunkard A, Berkowitz R, Wadden T, Tanrikut C, Reiss E, Young L. Binge eating disorder and the night-eating syndrome. Int J Obes Relat Metab Disord 1996; 20 $1-6$.

8 Stunkard AJ, Allison KC. Two forms of disordered eating in obesity: binge eating and night eating. Int J Obes Relat Metab Disord 2003; 27: 1-12.

9 Allison KC, Engel SG, Crosby RD, de ZM, O'Reardon JP, Wonderlich SA et al. Evaluation of diagnostic criteria for night eating syndrome using item response theory analysis. Eat Behav 2008; 9: 398-407.

10 Rand CS, Macgregor AM, Stunkard AJ. The night eating syndrome in the general population and among postoperative obesity surgery patients. Int J Eat Disord 1997; 22: 65-69.

11 Rand C, Kuldau J. Eating patterns in normal weight dividuals: bulimia, restrained eating and the night eating syndrome. Int J Eat Disord 1986; 5: 75-84.

12 Ceru-Bjork C, Andersson I, Rossner S. Night eating and nocturnal eating-two different or similar syndromes among obese patients? Int J Obes Relat Metab Disord 2001; 25: 365-372

13 Gluck ME, Geliebter A, Satov T. Night eating syndrome is associated with depression, low self-esteem, reduced daytime hunger, and less weight loss in obese outpatients. Obes Res 2001; 9: 264-267.

14 Adami GF, Campostano A, Marinari GM, Ravera G, Scopinaro N. Night eating in obesity: a descriptive study. Nutrition 2002; 18: 587-589.

15 Colles SL, Dixon JB, O'Brien PE. Grazing and loss of control related to eating: two high-risk factors following bariatric surgery. Obesity (Silver Spring) 2008; 16 615-622.

16 Powers PS, Perez A, Boyd F, Rosemurgy A. Eating pathology before and after bariatric surgery: a prospective study. Int J Eat Disord 1999; 25: 293-300.

17 Aronoff NJ, Geliebter A, Zammit G. Gender and body mass index as related to the night-eating syndrome in obese outpatients. J Am Diet Assoc 2001; 101: 102-104.

18 Napolitano MA, Head S, Babyak MA, Blumenthal JA. Binge eating disorder and night eating syndrome: psychological and behavioral characteristics. Int $J$ Eat Disord 2001; 30: 193-203.

19 Allison KC, Wadden TA, Sarwer DB, Fabricatore AN, Crerand CE, Gibbons LM et al. Night eating syndrome and binge eating disorder among persons seeking bariatric surgery: prevalence and related features. Obesity (Silver Spring) 2006(Suppl 2): 77S-82S.
20 Striegel-Moore $\mathrm{RH}$, Franko DL, Thompson D, Affenito S, Kraemer HC. Night eating: prevalence and demographic correlates. Obesity (Silver Spring) 2006; 14: 139-147.

21 Lundgren JD, Rempfer MV, Brown CE, Goetz J, Hamera E. The prevalence of night eating syndrome and binge eating disorder among overweight and obese individuals with serious mental illness. Psychiatry Res 2010; 175: 233-236.

22 Morse SA, Ciechanowski PS, Katon WJ, Hirsch IB. Isn't this just bedtime snacking? The potential adverse effects of night-eating symptoms on treatment adherence and outcomes in patients with diabetes. Diabetes Care 2006; 29: 1800-1804.

23 Birketvedt GS, Florholmen J, Sundsfjord J, Osterud B, Dinges D, Bilker W et al. Behavioral and neuroendocrine characteristics of the night-eating syndrome. JAMA 1999; 282: 657-663.

24 O'Reardon JP, Ringel BL, Dinges DF, Allison KC, Rogers NL, Martino NS et al. Circadian eating and sleeping patterns in the night eating syndrome. Obes Res 2004; 12: 1789-1796.

25 Allison KC, Ahima RS, O'Reardon JP, Dinges DF, Sharma V, Cummings DE et al. Neuroendocrine profiles associated with energy intake, sleep, and stress in the night eating syndrome. J Clin Endocrinol Metab 2005; 90: 6214-6217.

26 RC Boston, PJ Moate, KC Allison, JD Lundgren, Stunkard AJ. Modeling circadian rhythms of food intake by means of parametric deconvolution: results from studies of the night eating syndrome. Am J Clin Nutr 2008; 87: 1672-1677.

27 Allison KC, Grilo CM, Masheb RM, Stunkard AJ. Binge eating disorder and night eating syndrome: a comparative study of disordered eating. J Consult Clin Psychol 2005; 73: 1107-1115.

28 Lundgren JD, Allison KC, Stunkard AJ. Familial aggregation in the night eating syndrome. Int J Eat Disord 2006; 39: 516-518.

29 O'Reardon JP, Stunkard AJ, Allison KC. Clinical trial of sertraline in the treatment of night eating syndrome. Int J Eat Disord 2004; 35: 16-26.

30 Lichtman SW, Pisarska K, Berman ER, Pestone M, Dowling H, Offenbacher E et al. Discrepancy between self-reported and actual caloric intake and exercise in obese subjects. N Engl J Med 1992; 327: 1893-1898.

31 Lundgren JD, McCune A, Spresser C, Harkins P, Zolton L, Mandal K. Night eating patterns of individuals with eating disorders: Implications for conceptualizing the night eating syndrome. Psychiatry Res 2011; 186: 103-108.

32 de Zwaan M, Roerig DB, Crosby RD, Karaz S, Mitchell JE. Nighttime eating a descriptive study. Int J Eat Disord 2006; 39: 224-232.

33 Colles SL, Dixon JB, O'Brien PE. Night eating syndrome and nocturnal snacking: association with obesity, binge eating and psychological distress. Int $J$ Obes (London) 2007; 31: 1722-1730.

34 Striegel-Moore RH, Franko DL, Thompson D, Affenito S, May A, Kraemer HC. Exploring the typology of night eating syndrome. Int J Eat Disord 2008; 41: 411-418.

35 Allison KC, Lundgren JD, O'Reardon JP, Martino NS, Sarwer DB, Wadden TA et al. The night eating questionnaire (NEQ): psychometric properties of a measure of severity of the Night Eating Syndrome. Eat Behav 2008; 9: 62-72.

36 Lundgren JD, Allison KC, Crow S, O'Reardon JP, Berg KC, Galbraith J et al. Prevalence of the night eating syndrome in a psychiatric population. Am J Psychiatry 2006; 163: 156-158.

37 Greeno CG, Wing RR, Marcus MD. Nocturnal eating in binge eating disorder and matched-weight controls. Int J Eat Disord 1995; 18: 343-349.

38 Grilo CM, Masheb RM. Night-time eating in men and women with binge eating disorder. Behav Res Ther 2004; 42: 397-407.

39 Geliebter A. New developments in binge eating disorder and the night eating syndrome. Appetite 2002; 39: 175-177.

40 Lamerz A, Kuepper-Nybelen J, Bruning N, Wehle C, Trost-Brinkhues G, Brenner H et al. Prevalence of obesity, binge eating, and night eating in a cross-sectional field survey of 6-year-old children and their parents in a German urban population. J Child Psychol Psychiatry 2005; 46: 385-393.

41 Adami GF, Meneghelli A, Scopinaro N. Night eating and binge eating disorder in obese patients. Int J Eat Disord 1999; 25: 335-338.

42 Tholin S, Lindroos A, Tynelius P, Akerstedt T, Stunkard AJ, Bulik CM et al. Prevalence of night eating in obese and nonobese twins. Obesity (Silver Spring) 2009; 17: 1050-1055.

43 Root TL, Thornton LM, Lindroos AK, Stunkard AJ, Lichtenstein P, Pedersen NL et al Shared and unique genetic and environmental influences on binge eating and night eating: a Swedish twin study. Eat Behav 2010; 11: 92-98.

44 Dalgleish T, Tchanturia K, Serpell L, Hems S, de Silva P, Treasure J. Perceived control over events in the world in patients with eating disorders: a preliminary study. Pers Indiv Differ 2001; 31: 453-460.

45 Fairburn CG, Beglin SJ. Studies of the epidemiology of bulimia nervosa. Am J Psychiatry 1990; 147: 401-408.

46 Telch CF, Pratt EM, Niego SH. Obese women with binge eating disorder define the term binge. Int J Eat Disord 1998; 24: 313-317. 
47 Latner JD, Hildebrandt T, Rosewall JK, Chisholm AM, Hayashi K. Loss of control over eating reflects eating disturbances and general psychopathology. Behav Res Ther 2007; 45: 2203-2211.

48 Hildebrandt T, Latner J. Effect of self-monitoring on binge eating: treatment response or 'binge drift'? Eur Eat Disord Rev 2006; 14: 17-22.

49 Colles SL, Dixon JB, O'Brien PE. Loss of control is central to psychological disturbance associated with binge eating disorder. Obesity (Silver Spring) 2008; 16: 608-614.

50 Goldschmidt AB, Jones M, Manwaring JL, Luce KH, Osborne MI, Cunning D et al. The clinical significance of loss of control over eating in overweight adolescents. Int J Eat Disord 2008; 41: 153-158.

51 Birketvedt GS, Sundsfjord J, Florholmen JR. Hypothalamic-pituitary-adrenal axis in the night eating syndrome. Am J Physiol Endocrinol Metab 2002; 282: E366-E369.

52 The International Classification of Sleep Disorders. Diagnostic and Coding Manual, 2nd edn. American Academy of Sleep Medicine: Westchester, IL, 2005.

53 Winkelman JW. Treatment of nocturnal eating syndrome and sleep-related eating disorder with topiramate. Sleep Med 2003; 4: 243-246.

54 Vetrugno R, Manconi M, Ferini-Strambi L, Provini F, Plazzi G, Montagna P. Nocturnal eating: sleep-related eating disorder or night eating syndrome? A videopolysomnographic study. Sleep 2006; 29: 949-954.

55 Pawlow LA, O'Neil PM, Malcolm RJ. Night eating syndrome: effects of brief relaxation training on stress, mood, hunger, and eating patterns. Int $J$ Obes Relat Metab Disord 2003; 27: 970-978.

56 Allison KC, Grilo CM, Masheb RM, Stunkard AJ. High self-reported rates of neglect and emotional abuse, by persons with binge eating disorder and night eating syndrome. Behav Res Ther 2007; 45: 2874-2883.

57 Striegel-Moore RH, Rosselli F, Wilson GT, Perrin N, Harvey K, DeBar L. Nocturnal eating: association with binge eating, obesity, and psychological distress. Int J Eat Disord 2010; 43: 520-526.

58 Lundgren JD, Allison KC, O'Reardon JP, Stunkard AJ. A descriptive study of nonobese persons with night eating syndrome and a weight-matched comparison group. Eat Behav 2008; 9: 343-351.

59 Takeda E, Terao J, Nakaya Y, Miyamoto K, Baba Y, Chuman H et al. Stress control and human nutrition. J Med Invest 2004; 51: 139-145.

60 Sassaroli S, Ruggiero GM, Vinai P, Cardetti S, Carpegna G, Ferrato N et al. Daily and nightly anxiety among patients affected by night eating syndrome and binge eating disorder. Eat Disord 2009; 17: 140-145

61 Leskela US, Melartin TK, Lestela-Mielonen PS, Rytsala HJ, Sokero TP, Heikkinen ME et al. Life events, social support, and onset of major depressive episode in Finnish patients. J Nerv Ment Dis 2004; 192: 373-381.

62 Healey ES, Kales A, Monroe LJ, Bixler EO, Chamberlin K, Soldatos CR. Onset of insomnia: role of life-stress events. Psychosom Med 1981; 43: 439-451.

63 Stunkard A, Allison K, Lundgren J. Issues for DSM-V: night eating syndrome. Am J Psychiatry 2008; 165: 424

64 Tzischinsky O, Latzer Y. Nocturnal eating: prevalence features and night sleep among binge eating disorder and bulimia nervosa patients in Israel. Eur Eat Disord Rev 2004; 12: 101-109.

65 Nordin M, Knutsson A, Sundbom E, Stegmayr B. Psychosocial factors, gender, and sleep. J Occup Health Psychol 2005; 10: 54-63.

66 Ehlers CL, Frank E, Kupfer DJ. Social zeitgebers and biological rhythms. A unified approach to understanding the etiology of depression. Arch Gen Psychiatry 1988; 45: 948-952.

67 Marshall HM, Allison KC, O'Reardon JP, Birketvedt G, Stunkard AJ. Night eating syndrome among nonobese persons. Int J Eat Disord 2004; 35: 217-222.

68 Andersen GS, Stunkard AJ, Sorensen TI, Petersen L, Heitmann BL. Night eating and weight change in middle-aged men and women. Int J Obes Relat Metab Disord 2004; 28: 1338-1343.

69 Calugi S, Dalle GR, Marchesini G. Night eating syndrome in class II-III obesity: metabolic and psychopathological features. Int J Obes (London) 2009; 33: 899-904.

70 Whitaker RC, Wright JA, Pepe MS, Seidel KD, Dietz WH. Predicting obesity in young adulthood from childhood and parental obesity. N Engl J Med 1997; 337: 869-873.

71 Striegel-Moore RH, Dohm FA, Hook JM, Schreiber GB, Crawford PB, Daniels SR. Night eating syndrome in young adult women: prevalence and correlates. Int J Eat Disord 2005; 37: 200-206.

72 O'Reardon JP, Allison KC, Martino NS, Lundgren JD, Heo M, Stunkard AJ. A randomized, placebo-controlled trial of sertraline in the treatment of night eating syndrome. Am J Psychiatry 2006; 163: 893-898.

73 Stunkard A, Lu XY. Rapid changes in night eating: considering mechanisms. Eat Weight Disord 2010; 15: e2-e8.

74 Lundgren JD, Newberg AB, Allison KC, Wintering NA, Ploessl K, Stunkard AJ et al. 123I-ADAM SPECT imaging of serotonin transporter binding in patients with night eating syndrome: a preliminary report. Psychiatry Res 2008; 162: 214-220.
75 Allison KC, Stunkard A, Thier SL. Overcoming Night Eating Syndrome. New Harbinger Publications Inc.: Oakland, 2004.

76 Allison KC, Lundgren JD, Moore RH, O'Reardon JP, Stunkard AJ. Cognitive behavior therapy for night eating syndrome: a pilot study. Am J Psychother 2010; 64: 91-106.

77 Miyaoka T, Yasukawa R, Tsubouchi K, Miura S, Shimizu Y, Sukegawa T et al. Successful treatment of nocturnal eating/drinking syndrome with selective serotonin reuptake inhibitors. Int Clin Psychopharmacol 2003; 18: 175-177.

78 Spaggiari MC, Granella F, Parrino L, Marchesi C, Melli I, Terzano MG. Nocturnal eating syndrome in adults. Sleep 1994; 17: 339-344.

79 O'Brien B. Night eating syndrome and Gotu Kola. Ir Med J 2005; 98: 250-251.

80 Friedman S, Even C, Thuile J, Rouillon F, Guelfi JD. Night eating syndrome and winter seasonal affective disorder. Appetite 2006; 47: 119-122.

81 Friedman S, Even C, Dardennes R, Guelfi JD. Light therapy, nonseasonal depression, and night eating syndrome. Can J Psychiatry 2004; 49: 790.

82 Cooper-Kazaz R. Treatment of night eating syndrome with topiramate: dawn of a new day. J Clin Psychopharmacol 2012; 32: 143-145.

83 Devlin MJ, Goldfein JA, Flancbaum L, Bessler M, Eisenstadt R. Surgical management of obese patients with eating disorders: a survey of current practice. Obes Surg 2004; 14: 1252-1257.

84 Busetto L, Segato G, De LM, De MF, Foletto M, Vianello $M$ et al. Weight loss and postoperative complications in morbidly obese patients with binge eating disorder treated by laparoscopic adjustable gastric banding. Obes Surg 2005; 15: 195-201.

85 Latner JD, Wetzler S, Goodman ER, Glinski J. Gastric bypass in a low-income, inner-city population: eating disturbances and weight loss. Obes Res 2004; 12: 956-961.

86 Kretsch MJ, Fong AK, Green MW. Behavioral and body size correlates of energy intake underreporting by obese and normal-weight women. J Am Diet Assoc 1999; 99: 300-306.

87 Huang CJ, Hu HT, Fan YC, Liao YM, Tsai PS. Associations of breakfast skipping with obesity and health-related quality of life: evidence from a national survey in Taiwan. Int J Obes (London) 2010; 34: 720-725.

88 Cizza G, Skarulis M, Mignot E. A link between short sleep and obesity: building the evidence for causation. Sleep 2005; 28: 1217-1220.

89 Youngstedt SD, Kripke DF. Long sleep and mortality: rationale for sleep restriction. Sleep Med Rev 2004; 8: 159-174.

90 Taheri S. The link between short sleep duration and obesity: we should recommend more sleep to prevent obesity. Arch Dis Child 2006; 91: 881-884.

91 Hasler G, Buysse DJ, Klaghofer R, Gamma A, Ajdacic V, Eich D et al. The association between short sleep duration and obesity in young adults: a 13-year prospective study. Sleep 2004; 27: 661-666.

92 Patel SR, Blackwell T, Redline S, ncoli-Israel S, Cauley JA, Hillier TA et al. The association between sleep duration and obesity in older adults. Int J Obes (London) 2008; 32: 1825-1834.

93 Chaput JP, Drapeau V, Hetherington M, Lemieux S, Provencher V, Tremblay A. Psychobiological impact of a progressive weight loss program in obese men. Physiol Behav 2005; 86: 224-232.

94 Coughlin SR, Mawdsley L, Mugarza JA, Calverley PM, Wilding JP. Obstructive sleep apnoea is independently associated with an increased prevalence of metabolic syndrome. Eur Heart J 2004; 25: 735-741.

95 Bixler EO, Vgontzas AN, Lin HM, Calhoun SL, Vela-Bueno A, Kales A. Excessive daytime sleepiness in a general population sample: the role of sleep apnea, age, obesity, diabetes, and depression. J Clin Endocrinol Metab 2005; 90: 4510-4515.

96 Jennings JR, Muldoon MF, Hall M, Buysse DJ, Manuck SB. Self-reported sleep quality is associated with the metabolic syndrome. Sleep 2007; 30: 219-223.

97 Knutson KL, Ryden AM, Mander BA, Van CE. Role of sleep duration and quality in the risk and severity of type 2 diabetes mellitus. Arch Intern Med 2006; 166: 1768-1774.

98 Karp JF, Scott J, Houck P, Reynolds III CF , Kupfer DJ, Frank E. Pain predicts longer time to remission during treatment of recurrent depression. J Clin Psychiatry 2005; 66: 591-597.

99 Bower B, Bylsma LM, Morris BH, Rottenberg J. Poor reported sleep quality predicts low positive affect in daily life among healthy and mood-disordered persons. J Sleep Res 2010; 19: 323-332.

100 Drevets WC. Neuroimaging and neuropathological studies of depression: implications for the cognitive-emotional features of mood disorders. Curr Opin Neurobiol 2001; 11: 240-249.

101 Rosmond R. Obesity and depression: same disease, different names? Med Hypotheses 2004; 62: 976-979.

102 Blaine B. Does depression cause obesity?: A meta-analysis of longitudinal studies of depression and weight control. J Health Psychol 2008; 13: 1190-1197.

103 E Atlantis, M Baker. Obesity effects on depression: systematic review of epidemiological studies. Int J Obes (London) 2008; 32: 881-891. 
104 Dixon JB, Dixon ME, O'Brien PE. Depression in association with severe obesity: changes with weight loss. Arch Intern Med 2003; 163: 2058-2065.

105 Gangwisch JE, Malaspina D, Boden-Albala B, Heymsfield SB. Inadequate sleep as a risk factor for obesity: analyses of the NHANESI. Sleep 2005; 28: 1289-1296.

106 Taheri S, Lin L, Austin D, Young T, Mignot E. Short sleep duration is associated with reduced leptin, elevated ghrelin, and increased body mass index. PLoS Med 2004; 1: e62.

107 Vorona RD, Winn MP, Babineau TW, Eng BP, Feldman HR, Ware JC. Overweight and obese patients in a primary care population report less sleep than patients with a normal body mass index. Arch Intern Med 2005; 165: 25-30.

108 Palmese LB, Degeorge PC, Ratliff JC, Srihari VH, Wexler BE, Krystal AD et al. Insomnia is frequent in schizophrenia and associated with night eating and obesity. Schizophr Res 2011; 133: 238-243.
109 Olbrich K, Muhlhans B, Allison KC, Hahn EG, Schahin SP, de ZM. Night eating binge eating and related features in patients with obstructive sleep apnea syndrome. Eur Eat Disord Rev 2009; 17: 120-127.

110 Dalle GR, Calugi S, Ruocco A, Marchesini G. Night eating syndrome and weight loss outcome in obese patients. Int J Eat Disord 2011; 44: 150-156.

111 Garaulet M, Sanchez-Moreno C, Smith CE, Lee YC, Nicolas F, Ghrelin Ordovas JM. sleep reduction and evening preference: relationships to CLOCK 3111T/C SNP and weight loss. PLoS One 2011; 6: e17435.

112 Goncalves MD, Moore RH, Stunkard AJ, Allison KC. The treatment of night eating: the patient's perspective. Eur Eat Disord Rev 2009; 17: 184-190.

(c) This work is licensed under the Creative Commons AttributionSOMERIEHISRESERVED NonCommercial-Share Alike 3.0 Unported License. To view a copy of this license, visit http://creativecommons.org/licenses/by-nc-sa/3.0/ 